\title{
Das teorias das organizações à organização das teorias: do mundo da gestão ao mundo da educação ${ }^{1}$
}

\author{
From theories of organization to the organization of theories: from the "world \\ of management" to the "world of education \\ De las teorías de las organizaciones a la organización de las teorías: \\ de el mundo de la gestión al mundo de la educación
}

LUÍS LEANDRO DINIS

\begin{abstract}
Resumo: A evolução das concepções das organizações é transposta para uma grelha de leitura, fundada em três momentos na relação epistémica Indivíduo/ Organização, utilizada na "organização" das teorias organizacionais. Este trabalho de "organização" servirá para colocar, em paralelo, o "mundo da gestão" e o "mundo da educação", vistos sob o prisma das relações, cruzamentos e afastamentos entre as teorizações das respectivas realidades organizacionais. O resultado maior deste trabalho é a verificação de que as organizações educativas, mais do que quaisquer outras, têm todas as condições para, no futuro, virem a constituir-se como objecto de estudo privilegiado, no âmbito de novas teorias das organizações que despontam na transição de milénio.
\end{abstract}

Palavras chave: Teorias das organizações; individuo/organização; educação; gestão; organizações escolares.

\begin{abstract}
The evolution of the concept of organisations is transposed to an analytic framework based on three moments in the Individual/Organisation epistemological relationship, used to organize the theories. This work of "organization" will serve to place in parallel the "world of the management" and the "world of the education" and analyse their relationships, intersections and differences, among theories and their respective organisational realities. The main result of this work is the verification that educational organizations, more than any others, possess the requisites to become the more adequate object of study for the new organisational theories developing in the transition of the millennium.
\end{abstract}

Keywords: Theories of organizations; - individuals/organization; education; management; school organizations.

Resumen: La evolución en el pensamiento de las organizaciones es transpuesta a un marco de lectura, fundado en tres momentos de la relación

\footnotetext{
${ }^{1}$ Originalmente publicado na Revista Administração Educacional ( $\mathrm{n}^{\circ} 4$ - 2004), este texto é um dos capítulos - simultaneamente revisão da literatura e construção de quadro teórico - de uma dissertação de mestrado apresentada à Faculdade de Psicologia e de Ciências da Educação da Universidade de Lisboa, em 1998.
} 
epistémica individuo/organización, utilizado en la "organización” de las teorías organizacionales. Este trabajo de "organización” servirá para colocar en paralelo el "mundo de gestión" y el "mundo de la educación", visto bajo el prisma de las relaciones, cruces y las distancias entre la teorización de las respectivas realidades organizacionales. El resultado más importante de este trabajo es la verificación de que las organizaciones educativas más que cualquier otras tienen todas las condiciones para, en el futuro, se convirtieren en objeto privilegiado de estudio dentro del marco de nuevas teorías de las organizaciones que emergen en la transición del Milenio.

Palabras clave: Teorías de organizaciones; individuo/organización; educación; gestión; organización escolar.

\section{UMA PROPOSTA DE “LEITURA” DAS TEORIAS DAS ORGANIZAÇÕES}

No curto período de tempo que não chega a um século, as organizações, enquanto objecto de estudo científico, passaram, no entendimento que delas fazemos, de entidades exteriores às pessoas, como que possuindo existência própria, e como tal podendo ser estudadas olvidando a pessoa (GREENFIELD, 1985, p. 5240), a construções sociais, simbólicas, resultado da intersubjectividade e da interacção humana, cuja existência apenas se realiza na mente humana (idem, p. 5241).

Tão perto, no tempo cronológico, e tão longe, no tempo epistémico, se encontra a Filosofia Positiva de Auguste Comte (1798-1857) e a ideia durkheimiana de que os fenómenos sociais devem ser encarados como "coisas" (DURKHEIM, 1995: 302). Na esteira deste positivismo, não admira que as primeiras abordagens das organizações as tomassem como inteligíveis, apenas se consideradas como realidades exteriores ao homem.

A evolução das Teorias das Organizações e, como não poderia deixar de ser, da Sociologia, onde aquelas têm a sua origem, é paradigmática do que tem sido a evolução do conhecimento científico: do conhecimento do que the é fisicamente exterior, o homem retorna ao conhecimento de si próprio, para melhor conhecer o que o rodeia (SANTOS, 1993a, p. 87). Tudo faz sentido apenas na medida do próprio ser humano, objecto e sujeito de/para o conhecer (SANTOS, 1993b: 44). Descobrindo assim que nada lhe é exterior, que nada the é indiferente ou neutro. São estas questões epistemológicas que, em última análise, se encontram no cerne da evolução das teorias das organizações.

Qualquer raciocínio argumentativo, pela própria limitação humana, tem de, na multidimensionalidade que caracteriza o espaço dos possíveis epistemológicos, ser referenciado a um centro/eixo, qual ponto de partida 
(mesmo que o seu destino seja a auto-negação), a partir do qual seja possível o retorno necessário.

Aceitando como razoável tal postulado, parece-nos pertinente, pelo que antes fica dito, aceitar que tal centro/eixo deva ser ocupado pela próprio Ser Humano. Nestes termos, uma forma possível de "ler" a evolução das Teorias das Organizações é a de que elas se "movimentaram", crono-epistemologicamente, de forma nem sempre linear, num continuum onde, para efeitos de maior inteligibilidade, podem ser identificados três momentos particulares.

- O primeiro momento caracteriza-se por as organizações serem, não apenas concebidas como realidades exteriores às pessoas, passíveis de estudo autónomo face aos indivíduos, mas, por virtude da sua funcionalidade, assumirem uma transcendência social que leva a admitir, inclusive, a subordinação da pessoa aos desígnios da sua operacionalidade. No seu seio, os indivíduos operam de acordo com uma racionalidade que é da ordem da necessidade. Os instrumentos teórico-metodológicos, na sua abordagem, são os da ciência positivista. As organizações prosseguem buscando fins/objectivos que são, por vezes, descoincidentes com as finalidades para que foram concebidas. As abordagens clássicas da organização são deste período.

- No segundo momento, as organizações sendo ainda entendidas como entidades exteriores às pessoas, do ponto de vista epistémico, já o não são do ponto de vista social/cultural. As organizações estão "próximas" das pessoas. São habitadas (portanto, são "lugares") pelas pessoas. A sua racionalidade é da ordem da liberdade. Como produtos sociais, a fusão das racionalidades organização-indivíduo é a sua condição de existência percepcionada. Não existe uma racionalidade (imposta pela organização), antes existem várias racionalidades em permanente confronto. As pessoas "vivem" na organização, as pessoas vivem em organizações, sem contudo alienarem(-se) e exercerem o livre arbítrio, a sua liberdade de agir no seu seio. As organizações não são já realidades transcendentes, são apenas resultados da acção humana. Os instrumentos teóricometodológicos tradicionais não se adequam ao estudo das 
organizações entendidas desta forma. Os métodos qualitativos revelam-se mais ajustados a este tipo de abordagem.

- O terceiro momento, de que se vislumbram já alguns sinais, nas contribuições pós-modernistas de algumas abordagens das organizações tem, como aspecto fundamental, o pressuposto da fusão sócio-epistémica indivíduo-organização (GREENFIELD, 1985, p. 5241). Retomando o sentido da condição social do homem e a percepção de uma sociedade organizacional total, agora numa perspectiva intrinsecamente humana, tal fusão implicará a aceitação de que as organizações estão/são/no próprio homem. Decorrente deste postulado, encontra-se o imperativo teórico de que a possibilidade do estudo das organizações implica a necessidade/possibilidade de estudo da pessoa humana. O estudo das organizações passa pelo auto-estudo, pela auto-reflexão humana. A existir alguma racionalidade, ela irá para além da ordem da liberdade, será da ordem da afectividade. As organizações são produtos, não apenas sociais/culturais, mas igualmente simbólicos, cuja existência apenas faz sentido no autoconhecimento e consequente auto-produção.

Os três momentos e as suas características encontram-se no quadro resumo seguinte:

\section{Quadro 1 - Caracterização dos três momentos da evolução das Teorias das Organizações}

\begin{tabular}{|l|l|l|l|}
\cline { 2 - 4 } \multicolumn{1}{c|}{} & \multicolumn{1}{c|}{ FORA } & \multicolumn{1}{c|}{ PRÓXIMO } & \multicolumn{1}{c|}{ DENTRO } \\
\hline $\begin{array}{l}\text { Relação } \\
\text { Epistémica } \\
\begin{array}{l}\text { Indivíduo- } \\
\text { Organização }\end{array}\end{array}$ & $\begin{array}{l}\text { Exterioridade } \\
\text { As organizações são } \\
\text { exteriores às pessoas }\end{array}$ & $\begin{array}{l}\text { Proximidade } \\
\text { As organizações } \\
\text { são constituídas por } \\
\text { pessoas }\end{array}$ & $\begin{array}{l}\text { Interioridade } \\
\text { As organizações } \\
\text { são/estão as/nas } \\
\text { pessoas }\end{array}$ \\
\hline $\begin{array}{l}\text { Ordem da } \\
\text { Racionalidade }\end{array}$ & $\begin{array}{l}\text { única } \\
\text { necessidade } \\
\text { funcional }\end{array}$ & $\begin{array}{l}\text { múltiplas } \\
\text { liberdade social }\end{array}$ & $\begin{array}{l}\text { (a existir será da } \\
\text { afectividade } \\
\text { humana) }\end{array}$ \\
\hline
\end{tabular}




\begin{tabular}{|l|l|l|l|}
\hline $\begin{array}{l}\text { Consistência } \\
\text { Epistemológica }\end{array}$ & Artefactos Materiais & Artefactos Sociais & $\begin{array}{l}\text { Artefactos } \\
\text { Simbólicos }\end{array}$ \\
\hline
\end{tabular}

Ensaiamos, de seguida, uma leitura das teorias das organizações, inventariadas em alguma literatura, à luz deste nosso quadro de partida, organizando-as, do ponto de vista evolutivo, segundo as suas principais características. Exercício idêntico será feito depois, a propósito das teorias das organizações educativas.

\section{TEORIAS DAS ORGANIZAÇÕES}

Para tanto, torna-se necessário uma referência às diversas formas que, mais usualmente, têm sido utilizadas na classificação das teorias das organizações, por vezes referidas, também, como teorias da administração (BARROSO, 1993, p. 406). Três formas diferentes têm sido utilizadas na aproximação à classificação das teorias das organizações. Enquanto alguns autores se referem, genericamente, a abordagens, perspectivas, escolas, teorias e períodos (CHIAVENATO, 1983; CAMPBELL; NEWELL, 1985; BERNOUX, 1985; HUGHES, 1987; SCOTT, 1987; CURY, 1990; LUNEMBERG; ORNSTEIN, 1991; BURNES, 1992), outros autores organizam-nas em termos de paradigmas (CHANLAT ; SÉGUIN, 1992) e um terceiro grupo referenciam-nas em termos de metáforas (MORGAN, 1989).

Com propósitos interpretativos diferentes, em todos esses modos de aproximação, no entanto, é visível um denominador comum, em termos de designações que já entraram na terminologia da sociologia das organizações e da teoria das organizações. Elas correspondem a uma zona da teorização sobre as organizações que, substantivamente, contém já um corpus teórico estabelecido e consolidado.

No quadro seguinte (Quadro 2) damos conta das relações entre as diversas formas inventariadas, nos autores referidos. Dada a diversidade de fontes consideradas e a variedade de perspectivas, importa fazer algumas considerações sobre o referido quadro.

Uma primeira observação prende-se com o facto de apenas Chanlat; Séguin e Morgan considerarem, de forma clara, uma visão prospectiva de correntes ou perspectivas que, no âmbito das teorias da organização são, na actualidade, ainda apenas marginais, e que se identificam nalguns casos com o $3^{\circ}$ momento, considerado na nossa grelha de leitura.

Em segundo lugar, duas das tipologias são do âmbito das teorias da administração - Chiavenato e Cury -, não obstante, como se pode verificar, não 
apresentam diferenças significativas quando confrontadas com as restantes, cuja origem se pode considerar da área da sociologia das organizações.

\section{Quadro 2 - Classificação das Teorias das Organizações}

\begin{tabular}{|l|l|}
\hline \multicolumn{1}{|c|}{ Chiavenato, 1983 } & \multicolumn{1}{c|}{ Bernoux, 1985 } \\
\hline $\begin{array}{l}\text { Abordagem Clássica } \\
\text { - Administração Científica } \\
\text { - Teoria Clássica da Administração }\end{array}$ & Taylorismo \\
\hline Abordagem Humanística & Escola das Relações Humanas \\
\hline Abordagem Neo-Clássica & \\
\hline $\begin{array}{l}\text { Abordagem Estruturalista } \\
\text { - Modelo Burocrático } \\
\text { - Teoria Estruturalista da Organização }\end{array}$ & \\
\hline $\begin{array}{l}\text { Abordagem Comportamental } \\
\text { - Teoria Comportamental } \\
\text { - Teoria do Desenvolvimento Organizacional }\end{array}$ & Teoria das Necessidades e das \\
\hline $\begin{array}{l}\text { Abordagem Sistémica } \\
\text { - Teoria Matemática da Administração } \\
\text { - Teoria dos Sistemas }\end{array}$ & \\
\hline $\begin{array}{l}\text { Abordagem Contingencial } \\
\text { - Teoria da Contingência }\end{array}$ & Escola Sócio-Técnica \\
\hline & Sist. de Ação Concreta - \\
\hline
\end{tabular}

\begin{tabular}{|l|l|}
\hline \multicolumn{1}{|c|}{ Campbell, Newell, 1985 } & \multicolumn{1}{c|}{ Hughes, 1987} \\
\hline Gestão Industrial & Movimento da Gestão Científica \\
\hline & Teoria Clássica da Administração \\
\hline Relações Humanas & Perspectiva das Relações Humanas \\
\hline Estruturalismo & Organizações como Burocracias \\
\hline Sistemas Abertos & \\
\hline
\end{tabular}




\begin{tabular}{|l|l|}
\hline \multicolumn{1}{|c|}{ Cury, 1990 } & \multicolumn{1}{c|}{ Lunemberg, Ornstein, 1991 } \\
\hline Tradicionalistas & $\begin{array}{l}\text { Teoria Clássica da Organização } \\
\text { - Gestão Administrativa }\end{array}$ \\
\hline Revolução Ideológica & Abordagem das Relações Humanas \\
\hline Estruturalistas & Abordagem da Ciência Comportamental \\
\hline Behavioristas - Teorias e Modelo & \\
\hline Desenvolvimento Organizacional & Sistemas Abertos \\
\hline & \\
\hline Enfoque Contingencial & \\
\hline
\end{tabular}

\begin{tabular}{|c|c|}
\hline Burnes, 1992 & Scott, 1987 \\
\hline $\begin{array}{l}\text { Abordagem Clássica } \\
\text { - Gestão Científica } \\
\text { - Princípios da Organização } \\
\text { - Burocracia Weberiana }\end{array}$ & $\begin{array}{l}\text { Período 1900-30 - Modelos Racionais - } \\
\text { Fechados } \\
\text { - Gestão Científica } \\
\text { - Teoria da Burocracia } \\
\text { - Teoria da Administração }\end{array}$ \\
\hline Abordagem Relações Humanas & $\begin{array}{l}\text { Período 1930-60 - Modelos Naturais - } \\
\text { Fechados } \\
\text { - Relações Humanas } \\
\text { - Sistemas Cooperativos }\end{array}$ \\
\hline Abordagem Teoria da Contingência & $\begin{array}{l}\text { Período 1960-70 - Modelos Racionais - } \\
\text { Abertos } \\
\text { - Racionalidade limitada } \\
\text { - Teoria da Contingência }\end{array}$ \\
\hline Novas Perspectivas de Gestão & $\begin{array}{l}\text { Período } 1970 \text { - ... - Modelos Naturais - } \\
\text { Abertos } \\
\text { - Ordem negociada } \\
\text { - Ambiguidade e Escolha } \\
\text { - Sistemas Sócio-Técnicos } \\
\text { - Contingência Estratégica } \\
\text { - Ecologia das Populações } \\
\text { - Teoria Marxista }\end{array}$ \\
\hline
\end{tabular}




\begin{tabular}{|c|c|}
\hline Chanlat, Séguin, 1992 & Morgan, 1989 \\
\hline Paradigma Funcionalista: & Metáforas: A Organização vista como: \\
\hline \multirow[t]{2}{*}{ - Escola Clássica } & Máquina - Gestão Científica \\
\hline & Máquina - Escola Clássica da Gestão \\
\hline - Escola das Relações Humanas & Organismo - Necessidades das organizações \\
\hline \multicolumn{2}{|l|}{ - Teoria Weberiana da Burocracia } \\
\hline \multicolumn{2}{|l|}{ - Teoria dos Círculos Viciosos } \\
\hline \multicolumn{2}{|l|}{ - Escola da Tomada de Decisão } \\
\hline \multirow[t]{3}{*}{ - Escola Sistémica } & Organismo - Sistemas Abertos \\
\hline & Organismo - Teoria da Contingência \\
\hline & Cultura - Organização como Cultura \\
\hline \multicolumn{2}{|l|}{ Paradigma Crítico: } \\
\hline & $\begin{array}{l}\text { Organismo - Ecologia das Populações } \\
\text { Organismo - Variedade de Espécies }\end{array}$ \\
\hline & $\begin{array}{l}\text { Cérebro - Tratamento da Informação } \\
\text { Cérebro - Holograma: Autoorganização }\end{array}$ \\
\hline \multicolumn{2}{|l|}{ - Anarquismo } \\
\hline & Sistema Político \\
\hline & Instrumento de Dominação \\
\hline \multirow[t]{2}{*}{ - Existencialismo } & Fluxo e Informação - Autopoiesis \\
\hline & Fluxo e Informação: Causalidade Mútua \\
\hline \multirow[t]{2}{*}{ - Marxismo } & Fluxo e Informação: Dialéctica \\
\hline & Prisão do Psiquismo \\
\hline \multicolumn{2}{|l|}{ - Accionalismo } \\
\hline Paradigma da Complexidade & \\
\hline
\end{tabular}

A leitura dos quadros permite-nos identificar, grosso modo, a linha evolutiva das teorias das organizações, "arrumando-as" em 6 grupos de referência: a) Teorias Clássicas; b) Relações Humanas; c) Teorias de Sistemas; d) Teoria da Contingência; e) Sistemas de Acção Concreta; f) Teorias Emergentes. 


\section{TEORIAS CLÁSSICAS}

Neste grupo, incluímos a Abordagem Clássica (CHIAVENATO, 1983; BURNES, 1992); o Taylorismo (BERNOUX, 1985); a Gestão Industrial e o Estruturalismo (CAMPBELL ; NEWELL, 1985); o Movimento da Gestão Científica e as Organizações como Burocracias (HUGHES, 1987); os Tradicionalistas (CURY, 1990); a Teoria Clássica da Organização (LUNEMBERG ; ORNSTEIN, 1991); a Gestão Cientifica, a Teoria da Burocracia e a Teoria da Administração (SCOTT, 1987); a Burocracia Weberiana e os Círculos Viciosos Burocráticos (CHANLAT ; SÉGUIN, 1992) e a metáfora Organização como Máquina (MORGAN, 1989).

Neste particular, concordamos com a classificação de Burnes (1992), Lunemberg; Ornstein (1991) e Morgan (1989), que incluem o modelo burocrático de Max Weber nas teorias clássicas, ao lado de Frederick Taylor e de Henri Fayol.

Como mais adiante se explica, incluímos, também, a teoria dos círculos viciosos burocráticos (CHANLAT; SÉGUIN, 1992) na sua componente não apologética, isto é, excluindo Michel Crozier (1964).

Sendo quatro abordagens (redutíveis a três, se agregarmos as duas últimas) diferentes; pelos centros de interesse sobre que se debruçam, elas fundam-se nos mesmos princípios epistemológicos. Existe uma ordem universal que transcende o homem, nas suas relações entre si e com o mundo. O homem é, apenas, uma minúscula peça na grande engrenagem, que são as organizações. Nestes termos, torna-se imperativa a descoberta das leis e princípios que regulam e determinam o seu agir no seio das organizações.

A análise de tarefas realizada pelo casal Gilbreth (MARCH ; SIMON, 1979, p. 15-21; BURNES, 1992, p. 15-6), a separação da concepção da execução das tarefas (TAYLOR, 1992, p. 88-94), os princípios gerais de administração de Fayol (1992; p. 95-118) e a normalização e despersonalização burocrática (WEBER, 1992, p. 127), remetem todos para a um único objectivo que é, admitida a preexistência de uma ordem, de uma harmonia (BURNES, 1992, p. 23), à procura da melhor forma de funcionamento da organização.

O "One best way" procurado pelos clássicos era de natureza determinística e técnica. De tal forma que se dissipavam quaisquer conflitos entre os membros da organização: eles apenas tinham de se submeter aos ditames das regras, leis e princípios descobertos.

Assim,

com a organização científica, os verdadeiros interesses das suas partes são os mesmos; a prosperidade do empresário não pode realizar-se se não for acompanhada da do trabalhador, e vice-versa; é assim possível compatibilizar o 
que ambos desejam: ao operário, salários maiores, e ao patrão, uma mão-de-obra barata (TAYLOR, 1992, p. 80).

Segundo Fayol (1992, p. 95), “a saúde e o bom funcionamento do corpo social dependem de um certo número de condições designadas indiferentemente de princípios, leis ou regras".

Do mesmo modo, a universalidade do modelo burocrático de organização é defendida por Weber:

Em princípio, esta organização é igualmente aplicável - e é também historicamente comprovável (aproximando-se mais ou menos do tipo puro - às empresas lucrativas, às empresas não lucrativas ou a qualquer outro tipo de empresa, prosseguindo objectivos privados, ideais ou materiais (WEBER, 1992, p. 123).

Por seu lado, a Teoria dos Círculos Viciosos Burocráticos deteve-se na análise das disfunções do modelo burocrático weberiano. Ao detectar a inevitabilidade de comportamentos desconformes à rigidez e à impessoalidade burocrática, ao surgimento de castas no seio da organização, aos mínimos burocráticos, a disfunções no processo de delegação de poderes e à deterioração das relações pessoais (CHANLAT ; SÉGUIN, 1992; BALLÉ, 1992), a teoria dos círculos viciosos procura encontrar explicações e soluções para esses fenómenos sem, no entanto, colocar em causa os fundamentos do modelo:

Se as diferentes racionalidades que se defrontam podem estar na origem de disfunções, estas últimas nunca põem em causa a unidade funcional e o equilíbrio da organização. Elas obrigam, acima de tudo, à adopção de técnicas visando uma melhor integração dos indivíduos na organização (CHANLAT ; SÉGUIN, 1992, p. 23).

As três formas de abordagem, sendo complementares, permitem estabelecer um conjunto de ideias centrais acerca da abordagem clássica das organizações: a) Existe uma forma óptima para todas as organizações serem estruturadas e funcionarem; b) As normas e regras fundamentam a autoridade gestionária; c) As organizações são entidades racionais que, de forma congruente, perseguem objectivos e metas; d) As pessoas são motivadas apenas por interesses materiais; e) A falibilidade humana e as emoções podem ser eliminadas através da aplicação de leis e a eficiente organização do trabalho; f) A forma adequada e eficiente de organizar as actividades é conseguida com a divisão técnica e administrativa do trabalho, a diminuição da autonomia do trabalhador e o aumento do seu controlo. 


\section{RELAÇÕES HUMANAS}

Incluem-se, neste grupo, as Abordagens Comportamentais (CHIAVENATO, 1983; LUNEMBERG ; ORNSTEIN, 1991); a Revolução Ideológica, os Behavioristas, os Estruturalistas e o Desenvolvimento Organizacional (CURY, 1990); os Sistemas Cooperativos (SCOTT, 1987); a Escola da Tomada de Decisão (CHANLAT ; SÉGUIN, 1992); a Teoria das Necessidades e Motivações (BERNOUX, 1985); a metáfora Organismo - Necessidades das Organiz̧ações (MORGAN, 1989), para além, é claro, da escola das Relações Humanas (CHIAVENATO, 1983; BERNOUX, 1985; CAMPBELL ; NEWELL, 1985; HUGHES, 1987; SCOTT, 1987; LUNEMBERG ; ORNSTEIN, 1991; BURNES, 1992; CHANLAT ; SÉGUIN, 1992).

O que, a nosso ver, todas têm em comum é o facto de considerarem a dimensão humana da organização sem, no entanto, se libertarem do princípio da racionalidade organizacional como transcendente às "racionalidades humanas".

Isto é, a organização deixa de ser vista como um problema meramente técnico, passando a ser um problema humano, mas um problema humano cuja equação é resolvida ainda em termos técnicos. Os meios e instrumentos utilizados para a sua resolução passam pela novel Psicologia Experimental, na sua componente Social. Não é por acaso que a perspectiva psicológica predomina claramente na análise das organizações. Os principais representantes são, efectivamente, de matriz psicológica: Mayo, Maslow, Herzberg, McGregor, Argyris, Likert e Lewin, para citar apenas alguns. A perspectiva psicológica sobreleva, claramente, a sociológica, que tinha dominado o modelo burocrático weberiano.

O indivíduo não é mais entendido como uma peça inerte, sem alma. É, ainda e apenas, uma peça, mas uma peça na engrenagem que responde, não apenas, ou exclusivamente, aos estímulos materiais, mas a estímulos de ordem sócio-psicológica.

É a comprovação desta dimensão do comportamento humano, pelos estudos de Hawthorne, que se encontra na origem das teorias que englobamos no termo genérico de Relações Humanas. Tributária da Psicologia Experimental, a teoria das Relações Humanas considera o estudo do comportamento humano na organização (não como uma forma de exercício do livre arbítrio, mas como uma forma de descobrir os princípios e leis que regulam e comandam o funcionamento da dimensão informal das organizações, esperando conseguir encontrar, nessas novas condições, a melhor forma de fazer funcionar a organização).

Conseguindo determinar a melhor forma de compatibilizar as dimensões formal e informal da organização, desvendava-se uma "nova" ordem que, também neste caso, transcendia a natureza humana. É certo que as necessidades, 
motivações, desejo de afiliação, participação, cooperação e solidariedade eram considerados. Mas eram considerados como fenómenos essencialmente psicossociais, que se acreditava serem redutíveis a relações de causalidade e, portanto, passíveis de serem expressos em princípios gerais, de acordo com uma racionalidade instrumental. A descoberta dessas relações iria permitir o melhor desenho e desenvolvimento das organizações.

Para a consecução dos objectivos organizacionais, importa considerar o factor humano, quer procurando entender as sua necessidades (MASLOW), motivações (HERZBERG), desejo de afiliação e integração (LEWIN), cooperação (BARNARD) e participação (ARGYRIS), quer percebendo os processos solidarizantes (LIKERT), os processos de tomada de decisão e de racionalidade (limitada) e o confronto de racionalidades (FIEDLER, SIMON).

A situação permanece, no entanto, inalterada, pois o postulado da racionalidade da organização não é tocado nos seus fundamentos (CHANLAT; SÉGUIN, 1992, p. 25). A ideia de complementaridade entre a visão clássica das organizações e a das Relações Humanas dá bem a noção que, de facto, os fundamentos últimos de uma concepção da organização como maquinismo, regulável desde que se conheçam as leis internas que regem o seu funcionamento, se mantêm.

A diferença fundamental é que, na concepção dos teóricos das Relações Humanas, a máquina, que é a organização, é composta por peças não totalmente intercambiáveis, de forma imediata, já que não são inanimadas introduzindo, por via disso, alguma incerteza. Esta incerteza é, no entanto, controlável pelo conhecimento científico (técnico-psicológico: dinâmica de grupos; testes mentais e psico-técnicos; técnicas de motivação etc.) das leis que regem o comportamento humano.

O Desenvolvimento Organizacional e a Gestão por Objectivos, numa óptica do todo organizacional, são bem alguns exemplos da aplicação deste tipo de abordagem. É, aliás, em resultado da utilização, com objectivos alienatórios, desta visão da organização que, a breve trecho, fazem com que as Teorias das Relações Humanas sejam acusadas de constituir um instrumento de manipulação dos membros das organizações por quem detinha o poder de direcção.

Numa síntese bem conseguida, Burnes indica os elementos principais da abordagem das Relações Humanas:

O modelo das Relações Humanas considera três elementos centrais: - Liderança e comunicação; - Motivação intrínseca (bem como recompensas de natureza extrínseca); - Práticas e estruturas organizacionais que facilitam a flexibilidade e o envolvimento. A estes elementos são subjacentes duas hipóteses centrais: - As organizações são sistemas sociais complexos e não mecânicos; - Por isso, não podem ser efectivamente controladas através de uma supervisão apertada, regras 
rígidas e incentivos puramente materiais; - Os seres humanos têm necessidades afectivas tanto como necessidades económicas. As organizações e as condições de trabalho têm de ser compatíveis com a satisfação desses dois tipos de necessidades. Apenas desse forma se conseguirá que os trabalhadores tenham um desempenho eficiente e eficaz de acordo com os interesses da organização (BURNES, 1992, p. 37-8).

\section{TEORIAS DOS SISTEMAS ABERTOS}

Este grupo inclui as Teorias dos Sistemas (CHIAVENATO, 1983); Escola Sócio-Técnica (BERNOUX, 1985); Sistemas Sócio-Técnicos (SCOTT, 1987); Sistemas Abertos (CAMPBELL ; NEWELL, 1985; LUNEMBERG ; ORNSTEIN, 1991; MORGAN, 1989); Escola Sistémica (CHANLAT ; SÉGUIN, 1992) e Organização como Cultura (MORGAN, 1989).

Em boa verdade, poder-se-iam agrupar as Teorias dos Sistemas e as Teorias da Contingência, porque estas últimas são uma consequência natural da concepção das organizações como sistemas abertos sofrendo, portanto, influência permanente do seu meio ambiente, o que implica o carácter contingente do seu funcionamento em função de variáveis que não controla. Por outro lado, a concepção da organização como sistema aberto não teria qualquer sentido se não se retirassem desta "abertura" as devidas consequências, em termos das necessidades de adaptação ao meio ambiente, do qual ela recebe "inputs" e para o qual envia "outputs".

Entendemos, no entanto, nesta fase, considerá-las separadamente, pela importância que o desenvolvimento das teorias da contingência teve, em domínios não especificamente ligados à relação organização-meio ambiente, como seja o caso dos processos decisionais e dos comportamentos organizacionais.

As Teorias dos Sistemas Abertos constituem uma nova mudança de perspectiva, no estudo das organizações. Enquanto, nas abordagens anteriores, a análise se ficava pela organização em si mesma, como se fosse uma realidade isolada, a primeira como um problema técnico-mecânico, a segunda como um problema técnico-humano, mas sempre intra-muros; com a teoria dos sistemas abertos, o centro de interesse desloca-se para a organização como uma totalidade, nas suas relações com uma totalidade ainda maior, que é a sua envolvente exterior. O meio em que existe passa a constituir a principal fonte de incerteza para o funcionamento da organização (CHANLAT ; SÉGUIN, 1992, p. 27). As organizações, face a face às condições e exigências do meio, devem ser capazes de integrar as tensões que daí resultam, adaptando-se, sob pena de não sobreviverem (DE ROSNAY, 1975, p.132-9; HUGHES, 1987 p. 233; MORGAN, 1989, p. 42). 
Tanto como nas abordagens anteriores, talvez até mais, dada a maior visibilidade da organização como um "organismo" que "vive" num ambiente e que só sobrevive reagindo com ele, transformando-se, as organizações são consideradas como entidades externas, autónomas relativamente às pessoas. Este carácter de exterioridade ressalta da própria terminologia utilizada: “inputs", "outputs" para significar o que entra e o que sai da organização. O estatuto epistemológico da organização, mais do que anteriormente, é o de uma entidade que existe objectivamente, em oposição a todo o resto, os homens existem dentro ou fora da organização podendo, inclusive, ser considerados como inputs, tal como quaisquer outros (CHIAVENATO, 1983, p. 534; SILVER, 1983, p. 52).

Por esta nova perspectiva de análise das organizações, ficam completamente obliterados os processos internos. Isto é, as acções humanas permanecem no limbo da teorização, esperando por nova mudança de rumo, o que só virá a acontecer com a abordagem dos Sistemas de Acção Concreta (CROZIER ; FRIEDBERG, 1977; FRIEDBERG, 1993).

Não constitui, por isto, apesar de apresentar um avanço significativo na compreensão das organizações, a abordagem sistémica uma ruptura com a natueza funcionalista e positivista das análises anteriores. Apenas se verifica uma mudança de perspectiva e nível de análise: a deslocação do foco de interesse para a organização (sistema), como totalidade frente a outra totalidade (suprasistema o meio), de que é um componente. Mesmo a introdução da Cultura Organizacional, nos modelos mais desenvolvidos (RIBBINS, 1987,p. 232; CHANLAT ; SÉGUIN, 1992, p. 29; SANCHES, 1992), é feita numa perspectiva meramente funcional (RIBBINS, 1987, p. 233; OUCHI ; WILKINS, 1988, p. 224). Marginalmente, a atenção reverte, centrando-se nos elementos que compõem a organização: os seus sub-sistemas.

É em boa parte da consciência de que os componentes (sub-sistemas) não sofrem as mesmas influências do meio ambiente, nem a elas respondem de forma idêntica, que irão desenvolver-se estudos no sentido da explicação dos padrões de comportamentos da organização face ao ambiente. A procura das soluções de adaptação ao meio ambiente vai preocupar um vasto conjunto de teóricos, cujos estudos se encontram na origem das Teorias da Contingência.

\section{TEORIAS DA CONTINGÊNCIA}

Consideramos, neste grupo, as abordagens com o mesmo nome (CHIAVENATO, 1983; SCOTT, 1987; MORGAN, 1989; CURY, 1990; BURNES, 1992); a Ecologia das Populações (SCOTTT, 1987) e a Organização como Organismo - Ecologia das Populações e Variedade das Espécies (MORGAN, 1989). 
Como referimos antes, as teorias da contingência são, na sua vertente relações organização-meio, o corolário da aceitação dos pressupostos que subjazem à concepção das organizações como sistemas abertos.

Se se atender a que

quando se define uma organização formal como um sistema aberto, isto não significa simplesmente que a organização se encontra empenhada num processo de troca com os diversos elementos do seu meio ambiente, mas que essas trocas são essenciais para a viabilidade do sistema, a sua capacidade de reproduzir-se e transformar-se (CHANLAT ; SÉGUIN, 1987, p. 27),

torna-se claro que as organizações irão procurar adaptar o seu funcionamento e as suas estruturas às condições e exigências do meio ambiente.

Dadas as inevitáveis diversidade e alterações dos ambientes pertinentes para as empresas, não é possível pensar-se em respostas pré-concebidas. Como afirma Burnes,

A Teoria da Contingência é uma rejeição da abordagem "one best way" [...], ela é substituída pela perspectiva segundo a qual a estrutura e funcionamento das organizações estão dependentes ("Contingentes”) de variáveis situacionais com que depara [...] resulta assim que não há duas organizações que defrontem exactamente as mesmas contingências; por isso, se as suas situações são diferentes, deverão ser diferentes as suas estruturas e funcionamento [...]; consequentemente, "one best way" para todas as organizações é substituído pelo “one best way" para cada organização (BURNES, 1992, p. 39).

Este é, afinal, o princípio que vai orientar a investigação das influências que o meio ambiente exerce sobre as organizações, quer tenham a ver com a estratégia (CHANDLER), a dimensão (PUGH, BLAU ; SCHOENHER), a tecnologia (WOODWARD, PERROW), a natureza da incerteza ambiental (THOMPSON), as estruturas (BURN; STALKER), e a conexão interna (LAWRENCE; LORSCH); (CHIAVENATO, 1983, p. 545-79; CHANLAT; SÉGUIN, 1987, p. 30-3; MORGAN, 1989, p. 45-52; CURY, 1990, p. 56-72; BURNES, 1992, p. 42-51; BALLÉ, 1992; p. 84).

A ideia de que as organizações, para sobreviverem em ambientes mais ou menos hostis, mais ou menos turbulentos, instáveis ou complexos, necessitam ter determinadas aptidões e características, associadas a tipos específicos de estruturas e/ou configurações traz, como consequência lógica, a procura da melhor relação de organização-tipo de ambiente. Generalizam-se as investigações que tomam, como princípio fundamental, a assunção de que a cada ambiente corresponderia a sua espécie de organização. A ecologia das populações, a selecção das espécies, qual darwinismo organizacional, é uma decorrência das Teorias da Contingência. 
Por outro lado, o Desenvolvimento Organizacional é, igualmente, tributário das investigações levadas a cabo segundo os pressupostos destas teorias (PETITT, 1991 p. 176-7).

As teorias da contingência não tiveram, apenas, influência a nível das organizações, nas suas relações com o meio ambiente. Particularmente interessantes foram as investigações das relações entre os subsistemas componentes da organizações e, principalmente, as relativas aos processos decisionais e de liderança (SILVER, 1983, p. 152-174; JESUÍNO, 1987; LUNEMBERG; ORNSTEIN, 1991, p. 138).

Mesmo rejeitando a ideia de "one best way" universal, aplicável a todas as organizações e a todas as situações, fazendo depender a sobrevivência das organizações da sua capacidade de encontrarem a solução certa, no momento e lugar determinados, ou seja, a consecução dos equilíbrios internos e externos, as teorias da contingência fundam-se na convicção da existência de uma melhor solução para cada situação, que passa pelo equilíbrio, que é o mesmo que dizer uma "alguma" ordem e harmonia, ignorando, portanto, também ela, os fenómenos de poder e os interesses contraditórios, dinâmicos e irredutíveis a consensos, no seio da organização.

Para cada situação existe uma solução óptima. O problema consiste em identificar, claramente, a situação e, depois, procurar encontrar a solução adequada. Os objectivos e finalidades da organização são claros e possíveis de alcançar, conjugando soluções técnicas, humanas e administrativas, numa base de consenso, desde que seja encontrada a configuração (desenho contingencial) ideal da organização, face ao ambiente em que habita. A organização continua a transcender a natureza humana, existe para lá dela, de forma autónoma. É ela que reage às solicitações do ambiente, não as pessoas em si mesmas consideradas, com as suas idiossincrasias, as suas histórias, as suas emoções e afectos.

\section{SISTEMAS DE ACÇÃO CONCRETA}

Neste grupo, incluem-se a corrente como mesmo nome (BERNOUX, 1985); a Contingência Estratégica, a Ordem Negociada (SCOTT, 1987) e a organização como Sistema Politico e como Instrumento de Dominação (MORGAN, 1989).

A concepção das organizações como Sistemas de Aç̧ão Concreta opera uma ruptura fundamental com as teorias anteriores. Não poderíamos estar mais de acordo com Friedberg quando diz que

sem recuar aos erros das abordagens estruturalistas que declaravam alto e em bom som a morte do sujeito, numerosas são, com efeito, as abordagens, nomeadamente no mundo anglo-saxónico, que, ainda hoje, analisam as 
organizações - e portanto, também a acção social - como se elas existissem num mundo sem actores tangíveis, e como se elas tivessem leis impessoais de selecção ou de imitação (FRIEDBERG, 1993, p. 193).

A ruptura realiza-se por via do estatuto atribuído ao indivíduo nas organizações e, correlativamente, pela rejeição de toda e qualquer contingência que não seja radical. Sobre este último aspecto, logo de início, em L'acteur et le Système, Crozier ; Friedberg se demarcam, irredutivelmente, das Teorias da Contingência, ao afirmarem que

(...) não há nem fatalidade nem determinismo simples. As soluções não são, nem as melhores, nem mesmo as melhores relativamente a um "contexto" determinado. São sempre soluções contingentes no sentido radical do termo (CROZIER ; FRIEDBERG, 1977, p. 13).

Por outro lado, o estatuto do indivíduo na organização não é mais o de mero espectador, nem mesmo o de agente, mais ou menos passivo, input energético do sistema. Ele é o centro, é o actor, de onde partem e para onde convergem todos os processos organizacionais. O cenário/palco (a organização) perde visibilidade em favor do actor. No entanto, trata-se de um actor muito especial, pois o papel/função é da sua própria autoria. É, ao mesmo, actor/ encenador/realizador/autor/produtor. $O$ papel que desempenha é escrito e reescrito na acção pelo próprio, o que corresponde ao trajecto e projecto da pessoa na sua relação com os outros.

Os interesses e os jogos de interesses individuais e colectivos (MUCHIELLI, 1977, p. 21; DUBET, 1996, p. 86), as alianças e as estratégias fazem, deste actor, um actor estratégico (CROZIER ; FRIEDBERG, 1977; MORGAN, 1989, p. 198; PETITT, 1991, p. 137; FRIEDBERG, 1993, p. 193), que cria a organização (BERNOUX, 1985, p. 149), ao criar as redes de relações na interacção social, com os outros (actores), todos eles portadores de liberdade e autonomia, apenas auto-limitadas pelo "sistema de regulação das relações" (BERNOUX, 1985, p. 150) e pelas estratégias que desenvolvem no sentido da consecução dos seus próprios objectivos.

Toda a organização é composta de actores estruturando as suas acções num modelo tão interactivo quanto interdependente, se querem funcionar "bem". A maneira como este conjunto humano estrutura as suas relações designaremos por sistema de acção concreta, ou então subsistema de acção concreta (BERNOUX, 1985, p. 149).

Como se percebe, a abordagem das organizações, desta forma, remete para a aceitação do conflito, luta e controlo do que (MUCHIELLI, 1977,p. 
21-2; MORGAN, 1989, p. 166) Crozier e Friedberg designam por "zonas de incerteza" (CROZIER ; FRIEDBERG, 1977, p. 70-6; MORGAN, 1989, p. 194-5). A luta pela conquista do poder é uma decorrência dos pressupostos anteriores. As alianças estratégicas entre actores, para alcançarem os meios e as posições no seio do sistema de relações, são fenómenos sociais característicos das organizações.

O outro elemento será o sistema de regulação de relações, isto é, as regras a partir das quais os actores conhecem as possibilidades que têm de organizar a sua acção para resolver as questões que se colocam ao conjunto social. Os actores não são entidades abstractas, antes pelo contrário, quando participam na elaboração das definições de si (FRIEDBERG, 1993, p. 198) e dos outros e quando inventam condutas, na construção do sistema de relações, fazem-no de acordo com um duplo referencial: a sua história pessoal e as oportunidades e constrangimentos da situação (FRIEDBERG, 1993, p. 214). Cada actor é portador da sua própria historicidade, da sua própria racionalidade, irredutíveis a categorias colectivas sob a forma de racionalidade da organização. Neste sentido, Friedberg admite que a noção de sistema de ação concreta “(...) estrutura a acção colectiva dos homens, quer este último se encontre no seio de uma organização formal, ou num contexto de acção mais fluído" (FRIEDBERG, 1993, p. 165).

Assim, as organizações, no sentido usual do termo, não são mais do que um determinado tipo de sistema de acção concreta. O que sobressai, desta forma de ver a organização é, de imediato, a ideia de que as organizações não são exteriores ao homem, antes são um produto da sua acção. Não têm existência própria. Como tal não, faz mais sentido falar na acção do homem na organização. Deverá, antes, falar-se na acção organizada do homem. Não existem uma "ordem", princípios ou leis a descobrir e a dominar. Existe, apenas, a acção humana, com tudo o que isto significa de racionalidade, intuição, afecto, emoção e subjectividade.

\section{TEORIAS EMERGENTES}

Mais do que teorias são correntes ou linhas prospectivas, que se desenham para um entendimento das organizações em perfeita ruptura com o paradigma positivista. O carácter heterogéneo e difuso dessas perspectivas torna difícil a sua classificação. Digamos que a característica comum é o facto de não serem enquadráveis nas abordagens anteriores. A sua inclusão num mesmo grupo, com base num tal critério, convenhamos, é um procedimento cuja validade se apresenta muito duvidosa. Temos consciência disto, mas, dada a inexistência de corpus teóricos claramente definidos, no âmbito das propostas potencialmente 
percebidas e antevistas nas suas formulações, ainda muito genéricas, não nos deixa alternativa.

Apenas três autores, e de forma muito diferente, abordam perspectivas inovadoras na aproximação das organizações. Assim são incluídas, nestas "teorias" emergentes, o Anarquismo, o Existencialismo, o Marxismo, o Accionalismo, o Paradigma da Complexidade (CHANLAT ; SÉGUIN, 1992); a Teoria Marxista e a Ambiguidade e Escolha (SCOTT, 1987) e as metáforas Cérebro, Fluxo e Informação e Prisão do Psiquismo (MORGAN, 1989). Sobre as primeiras importa, desde logo, referir que, tendo todas surgido num contexto de forte implantação do positivismo, permaneceram sempre na contracorrente e foram, de algum modo, marginalizadas ou apropriadas e socializadas pelo mundo científico e académico, tornando-as, social e cientificamente inócuas, nas suas propostas originais. A este "apagamento" não é estranha a hegemonia anglo-saxónica e, nomeadamente, a americana, bem como o difícil diálogo entre europeus e americanos, no domínio da sociologia das organizações. Isto permite a Chanlat; Séguin afirmarem que

\begin{abstract}
profundamente refractárias à filosofia crítica europeia, em particular ao marxismo, marcadas por um evolucionismo linear que define os Estados Unidos como o modelo a seguir, e por uma ideologia conservadora, as teorias da organização, sob a influência do funcionalismo americano, fecham a porta durante numerosos anos ao pensamento crítico (CHANLAT ; SÉGUIN, 1992, p. 43).
\end{abstract}

Actualmente, com a anunciada falência do paradigma positivista e da ciência moderna, elas encontram terreno favorável para começarem a imporse. A reaparição e reapreciação de todas estas correntes resultam, de algum modo, de uma ciência social crítica (ENGLAND, 1989), enquadrada por um movimento mais global, de uma epistemologia pós-modernista que propugna a falência das dicotomias e oposições que têm caracterizado o positivismo: social/ natural; prática/teoria; qualidade/quantidade; sujeito/objecto; local/global etc. (SANTOS, 1993a).

É neste ambiente que a emergência do indivíduo-pessoa, centro de todo o interesse daquelas correntes de pensamento, polarizado na Liberdade (GUÉRIN, sd, p. 31; BAKOUNINE, sd, p. 57, KROPOTKINE, sd, p. 91; PROUDHON, 1992, p. 326; MALATESTA, 1992, p. 332), na Praxis (LEFEBVRE, 1968, p. 27; PIETTRE, 1969, p. 47; MARX, 1982, p. 3), no Projecto (SARTRE, sd, p. 243; WAHL, 1962, p. 47,138; AUDRY, 1972, p. 87-95; BOUTINET, 1990, p. 38-54) e na Acção (TOURAINE, 1974, p. 33; MUCHIELLI, 1977, p. 22; ANSART, 1990, p. 57; CHANLAT ; SÉGUIN, 1992, p. 63), dá corpo a uma mudança de perspectiva, devolvendo-lhe o estatuto epistemológico focal, com os seus 
conflitos, as suas contradições e as suas perplexidades, com que povoam a construção e representação da realidade social.

Entretanto, estas perspectivas poderão nem sequer vir a desenvolver-se de forma completa, dada a rapidez com que se verificam as mutações sociais e as construções teóricas que lhes dão vida. Tanto assim é que, segundo Chanlat ; Séguin, um novo paradigma está emergindo: o Paradigma da Complexidade.

A ordem não existe mais, não se impõe de forma absoluta, é relativa e relacional [...]; esta nova corrente que procura unir numa relação dialéctica o que a sociedade, até agora, tinha separado: a ordem e a desordem, as ciências humanas e as ciências físicas (CHANLAT ; SÉGUIN, 1992, p. 71-2).

Nesta linha, apontam os contributos pós-modernistas, quando afirmam a totalidade do conhecimento que, sendo o conhecimento total é, também, local, que o "total" está inscrito no "local", que as oposições tradicionais e características da ciência moderna se encontram vazias de sentido. Que "[...] não existe natureza humana, porque toda a natureza é humana" e que "[...] podemos afirmar hoje que o objecto é a continuação do sujeito por outros meios" (SANTOS, 1993a: $44,52)$.

Quanto às metáforas apresentadas por Morgan em Images de l'Organization, é particularmente interessante, na linha do Paradigma da Complexidade, a imagem da organização como Fluxo e Informação (nas três vertentes consideradas; autopoiesis, causalidade mútua e dialéctica), que nos remetem para os conceitos de ordem implicada e ordem explicada e de holomovimento e holofluxo de David Bohm:

A ordem implicada é considerada como um processo criador tal como um holograma, caracteriza-se por o conteúdo do todo no todo. Bohm serve-se dos termos holomovimento e holofluxo para exprimir a natureza indivisa e movente desta ordem, que é a fonte geradora das formas explicadas. Estas formas... têm a aparência da estabilidade encontrando-se sustentadas pelo fluxo e pela mudança.” (MORGAN, 1989, p. 269-270).

Os conceitos de auto-referência, circularidade e autonomia, fundamentos da autopoiesis de Maturana ; Varela (MORGAN, 1989, p. 273), capacidade de auto-criação e auto-renovação são de extrema importância para a uma nova compreensão e concepção de organização. Assim, a interacção da organização com o seu "meio ambiente" é um reflexo e uma parte de si mesma. A distinção entre organização e meio perde sentido: "é por isso, no fim de contas, que não faz sentido dizer que um sistema interage com um meio ambiente externo. Com efeito, as trocas de um sistema com um meio ambiente são na realidade trocas consigo mesmo" (MORGAN, 1989, p. 276). 
É uma nova compreensão de que o "local" e o "global" são uma e mesma realidade.

Analogamente, o indivíduo, na organização, não é mais um elemento, um componente da organização. É ele próprio a organização. A organização existe nele e para ele. De resto, as restantes metáforas, organização como Prisão do Psiquismo e como Cérebro, relevam de sentidos homólogos. Assim, "ao interpretar a significação inconsciente da relação entre imortalidade e a organização, damonos conta que tentando gerir e organizar o nosso universo, tentamos na realidade gerir e organizarmos a nós próprios" (MORGAN, 1989, p. 229), mostrando bem as relações entre as pulsões inconscientes do homem e as organizações como formas de projecção e identificação auto-referencial.

Ao insistir sobre os conceitos de auto-organização e visão holográfica da organização, Morgan, na metáfora do Cérebro, traz à discussão uma ideia cara aos pós-modernistas, isto é, a de que o todo está inscrito nas partes, o que, de novo, se pode verter para a concepção de que a distinção entre o indivíduo/ organização não parece ser um instrumento teórico adequado à aproximação e compreensão das organizações: "as organizações têm necessidade de um "ethos" e de uma visão holográfica graças às quais as atitudes e as competências que se espera do "todo" estarão inscritas em cada "parte" (MORGAN, 1989, p. 114).

Num exercício cuja finalidade é a de conseguir um resumo interpretativo e arrumo visual de conjunto, e tendo consciência de que as zonas de intersecção teórica percorrem, nomeadamente, em termos de autores mais representativos, nalguns casos, todo o continuum poderíamos, de acordo com a grelha de leitura adoptada, "organizar" as teorias das organizações de acordo com o quadro seguinte:

Quadro 3 - "Localização" das Teorias das Organizações

\begin{tabular}{|l|l|l|}
\hline \multicolumn{1}{|c|}{ FORA } & \multicolumn{1}{|c|}{ PRÓXIMO } & \multicolumn{1}{c|}{ DENTRO } \\
\hline - Teorias Clássicas & $\bullet$ Sistemas de & $\bullet$ Teorias Emergentes \\
- Relações Humanas & Acção Concreta & \\
- Teorias Contingenciais & & \\
- Teorias Sistémicas & & \\
\hline
\end{tabular}

\section{DAS TEORIAS DAS ORGANIZAÇÕES EDUCATIVAS}

A evolução do conhecimento e pensamento sobre as organizações educativas, bem como a teorização sobre a administração das organizações escolares acompanha, de perto, a história das teorias das organizações enunciada antes. Não obstante as repetidas afirmações de que as organizações educativas 
(as escolas especificamente) e, portanto, a administração educacional têm características próprias (HALPIN, 1967, p. 10; ECKER, 1985, p. 5256; BUSH, 1986, p. 4; SAENZ BARRIO, 1993, p. 20), verifica-se que os contributos da investigação sobre a administração educacional para as teorias das organizações e da administração, em geral, têm sido bastante reduzidos. Exceptuando os casos dos conceitos de sistema debilmente acoplado (WEICK, 1976; ECKER, 1985, p. 5257) e de anarquia organizada (COHEN, MARCH ; OLSEN, 1972; ECKER, 1985, p. 5257; FRIEDBERG, 1993, p. 70), esses contributos são, praticamente, inexistentes. Por exemplo, em mais de oitocentos autores referenciados por Morgan na sua obra Images de l'Organizations encontrámos referências a Weick, Cohen, March e Olsen, exactamente a propósito daqueles contributos, sendo que, em contrapartida, não existem quaisquer referências a autores como Baldridge, Ball, Bates, Bell, Best, Caldwell, Croft, Culbertson, Getzels, Glatter, Greenfield, Griffiths, Guba, Hoyle, Halpin, Hodgkinson, Milikan, Watkins, Willower, Woods e muitos outros, da área da administração educacional.

A consulta de qualquer obra geral sobre Administração Educacional mostrar-nos-á, porventura, uma situação inversa. Para além de mostrar que grande parte da teorização sobre as organizações educativas se faz a partir de uma matriz que tem, nas organizações empresariais, o seu principal suporte mostra-nos, também, alguma dificuldade na aquisição do direito de cidadania no seio da sociologia das organizações. Entretanto, novas perspectivas estão emergindo na teorização das organizações e administração educativas que, num futuro próximo, poderão vir a desempenhar um papel inovador e a alterar o panorama da sociologia das organizações (ALLISON, 1983, p. 17). Julgamos que, particularmente, as organizações educativas proporcionam objecto de estudo muito rico, no âmbito das "teorias emergentes" referidas antes. Isto é, aliás, visível nas perspectivas, modelos e paradigmas que, inventariadas mais adiante, onde as dimensões cultural, política, simbólica, ética, emancipatória, de ambiguidade (BALDRIDGE ; DEAL, 1983; BUSH, 1989; EVERS ; LAKOMSKI, 1991; BOTTERY, 1992) aparecem referenciadas em termos já expressivos.

Num conjunto de 14 autores (BURREL ; MORGAN, 1979; PFEIFFER, 1982, citado por BORREL FELIP, 1989; SILVER, 1983; BOLMAN ; DEAL, 1984, citado por BORREL FELIP, 1989; OGWA, 1985; ECKER, 1985; BUSH, 1986; RIBBINS, 1987; HUGHES, 1987; ENGLAND, 1989; TYLER, 1988; BORREL FELIP, 1989; BARROSO, 1993; 1995b; SAENZ BARRIO, 1993), apesar da grande diversidade de critérios seguidos nas abordagens, grosso modo, foi possível identificar dois grandes grupos de aproximações às teorias das organizações educativas e da administração educacional (Quadro 4). 
Um primeiro grupo é constituído pelos 6 primeiros autores citados antes. Os quatro primeiros consideram 3 momentos na evolução das teorias: Ribbins e England, sob designação de Paradigmas; Hughes e Barroso, por seu lado, identificam-nos sob a forma de períodos.

\section{Quadro 4 - Teorias, Modelos e Períodos das Teorias das Organizações Educativas}

\begin{tabular}{|c|l|l|}
\hline \multicolumn{1}{|c|}{ England, 1989 } & \multicolumn{1}{|c|}{ Barroso, 1993, 1995b } \\
\hline 1 & $\begin{array}{l}\text { Positivismo e Ciência Empírico- } \\
\text { Analítica }\end{array}$ & $\begin{array}{l}1^{\circ} \text { Período -...- 1950 } \\
\text { (Teorias Clássicas - Relações Humanas) }\end{array}$ \\
\hline 2 & & \\
\hline 3 & & $\begin{array}{l}2^{\circ} \text { Período - 1950-1970 } \\
\text { (Marcado pelo New Movement) }\end{array}$ \\
\hline 4 & $\begin{array}{l}3^{\circ} \text { Período - 1970-... (Marcado pelas } \\
\text { críticas de Greenfield) }\end{array}$ \\
\hline 5 & $\begin{array}{l}\text { Racionalidade Prática e Ciência } \\
\text { Hermenêutico-Interpretativa }\end{array}$ & $\begin{array}{l}\text { Prática Crítica e Ciência Social } \\
\text { Crítica }\end{array}$ \\
\hline
\end{tabular}

\begin{tabular}{|l|l|l|}
\hline & \multicolumn{1}{|c|}{ Ribbins, 1987 } & \multicolumn{1}{|c|}{ Hughes, 1987 } \\
\hline 1 & $\begin{array}{l}\text { Assunção do Consenso } \\
\text { (Sistemas Fechados/Abertos; } \\
\text { Sistemas debilmente acoplados) }\end{array}$ & $\begin{array}{l}\text { Fundamentos Empíricos } \\
- \text { Teorias Clássicas } \\
\text { - Burocracia } \\
\text { - Relações Humanas } \\
\text { - Aplicação à Administração Educacional }\end{array}$ \\
\hline 2 & & Paradigma do New Movement \\
\hline 3 & $\begin{array}{l}\text { Ordem empiricamente } \\
\text { Contingente } \\
\text { (Interaccionismo Simbólico; } \\
\text { Fenomenologia Social; } \\
\text { Etnometodologia) }\end{array}$ & \\
\hline 4 & \\
\hline
\end{tabular}




\begin{tabular}{|l|l|l|}
\hline 6 & Assunção do Conflito & Perspectivas Contemporâneas \\
& (Teoria Marxista; Teoria & - Abordagem Multidisciplinar \\
Crítica) & - Diversidade de Modelos Estruturais \\
& & - Modelos Políticos - Economia da Educação \\
& - Micro-política/outras Micro-perspectivas \\
\hline
\end{tabular}

\begin{tabular}{|c|c|c|}
\hline & Burrel ; Morgan, 1979 & $\begin{array}{c}\text { Pfeffer, } 1982 \text { apud Borrel Felipe, } \\
1989\end{array}$ \\
\hline 1 & $\begin{array}{l}\text { Funcionalismo } \\
\text { (Pluralismo - Teoria das disfunções } \\
\text { burocráticas - Teorias do Sistema } \\
\text { Social - Objectivismo - Marco de } \\
\text { Acção de referência) }\end{array}$ & $\begin{array}{l}\text { Racional - Indivíduo } \\
\text { (Teoria expectante - Estabelecimento } \\
\text { de metas - Teorias políticas - Design de } \\
\text { Tarefas) }\end{array}$ \\
\hline 2 & & $\begin{array}{l}\text { Ambiente - Indivíduo } \\
\text { (Condicionamento operante - Teoria } \\
\text { da aprendizagem social - Socialização - } \\
\text { Teoria dos papéis - Efeitos do contexto } \\
\text { social - Racionalidade retrospectiva - } \\
\text { Processo informático) }\end{array}$ \\
\hline 3 & & $\begin{array}{l}\text { Racional - Organização Total } \\
\text { (Teorias estruturais e contingência - Pers- } \\
\text { pectivas marxistas - Falhas de mercado e } \\
\text { custos de transacção) }\end{array}$ \\
\hline 4 & & $\begin{array}{l}\text { Ambiente - Organização Total } \\
\text { (Ecologia das populações - Dependência } \\
\text { de recursos) }\end{array}$ \\
\hline 5 & $\begin{array}{l}\text { Interpretativo } \\
\text { (Etnometodologia - Fenomenologia } \\
\text { da interpretação simbólica - } \\
\text { Humanismo Radical - Teoria da } \\
\text { Anti-organização) }\end{array}$ & $\begin{array}{l}\text { Construções Sociais - Indivíduo } \\
\text { (Etnometodologia - Teorias cognitivas } \\
\text { organizacionais - A Linguagem nas } \\
\text { organizações - Processos baseados no } \\
\text { afecto) }\end{array}$ \\
\hline 6 & $\begin{array}{l}\text { Estruturalismo Radical } \\
\text { (Sociologia da mudança radical - } \\
\text { Marxismo - Teoria da organização } \\
\text { radical) }\end{array}$ & $\begin{array}{l}\text { Construções Sociais - Organização Total } \\
\text { (Organizações como paradigmas - Pro- } \\
\text { cesso de decisão e teorias administrativas } \\
\text { - Teoria da Institucionalização) }\end{array}$ \\
\hline
\end{tabular}




\begin{tabular}{|l|l|l|}
\hline \multicolumn{1}{|c|}{ Saenz Barrio, 1993 } & \multicolumn{1}{c|}{ Silver, 1983 } \\
\hline 1 & Modelo Burocrático & Burocracia \\
\hline 2 & \multicolumn{1}{|c|}{ Organização } & $\begin{array}{l}\text { Abordagem Comportamental } \\
\text { Perspectiva Motivacional } \\
\text { Teoria do "Expectancy" }\end{array}$ \\
\hline 3 & $\begin{array}{l}\text { Escola, } \\
\text { Institucionalizada da "Compliance" }\end{array}$ \\
\hline 4 & $\begin{array}{l}\text { Escola como Eco-Sistema } \\
\text { Teoria Axiomática }\end{array}$ & $\begin{array}{l}\text { Teoria do Sistema Social } \\
\text { Clima Organizacional } \\
\text { Abordagem Contingencial }\end{array}$ \\
\hline 5 & $\begin{array}{l}\text { Escola como Anarquia } \\
\text { Organizada }\end{array}$ & $\begin{array}{l}\text { Escola como espaço Micro- } \\
\text { Político }\end{array}$ \\
\hline
\end{tabular}

\begin{tabular}{|c|c|c|}
\hline & $\begin{array}{c}\text { Ogawa, } 1985 \text { - Ecker, } \\
1985\end{array}$ & Bush, 1989 \\
\hline 1 & Modelo Racional & $\begin{array}{l}\text { Modelos Formais: } \\
\text { - Estruturais - Sistémicos - Burocráticos } \\
\text { - Racionais - Hierárquicos }\end{array}$ \\
\hline 2 & Modelo Sistema Natural & \\
\hline 3 & & Modelos Democráticos \\
\hline 4 & Modelo Sistemas Abertos & \\
\hline 5 & $\begin{array}{l}\text { Anarquia Organizada } \\
\text { Sistemas Debilmente } \\
\text { Acoplados }\end{array}$ & $\begin{array}{l}\text { Modelos de Ambiguidade } \\
\text { Modelos Subjectivos }\end{array}$ \\
\hline 6 & & Modelos Políticos \\
\hline
\end{tabular}

\begin{tabular}{|c|l|l|}
\hline & $\begin{array}{c}\text { Bolman; Deal, 1984 apud } \\
\text { BorrelFelip, 1989 }\end{array}$ & \multicolumn{1}{|c|}{ Tyler, 1988 } \\
\hline 1 & $\begin{array}{l}\text { Sistemas Racionais ou } \\
\text { Estruturais }\end{array}$ & $\begin{array}{l}\text { Escola - Organização Complexa - Modelo } \\
\text { Burocrático }\end{array}$ \\
\hline 2 & Recursos Humanos & \\
\hline 3 & & \\
\hline
\end{tabular}




\begin{tabular}{|l|l|l|}
\hline 4 & & $\begin{array}{l}\text { Escola - Organização Complexa - Modelo } \\
\text { Contingencial }\end{array}$ \\
\hline 5 & Simbólico & $\begin{array}{l}\text { Escola - Organização Complexa - Sistema } \\
\text { Debilmente Acoplado }\end{array}$ \\
\hline 6 & Político & \\
\hline
\end{tabular}

\begin{tabular}{|l|l|}
\hline & \multicolumn{1}{|c|}{ Borrel Felip, 1989 } \\
\hline 1 & Modelos Racionais \\
\hline 2 & $\begin{array}{l}\text { Modelos Naturais } \\
\text { Modelos dos Recursos Humanos }\end{array}$ \\
\hline 3 & Modelos Estruturais \\
\hline 4 & Modelos dos Sistemas \\
\hline 5 & Modelos Simbólicos \\
\hline 6 & Modelos Políticos \\
\hline
\end{tabular}

Os restantes dois autores, não especificamente da área da administração educacional, consideram quatro perspectivas (BURREL; MORGAN), que reduzimos a três, como consta do quadro, numa aproximação às abordagens realizadas pelos autores anteriores e seis perspectivas, pelo cruzamento de duas dimensões, nível de análise e perspectiva de acção, consideradas pela teoria (PFEFFER).

Esta classificação mostrou-se completamente atípica e impossível de comparação com as anteriores revelando, no entanto, algumas afinidades, em alguns aspectos, com as classificações (modelos) do segundo grupo de abordagens.

Não obstante os critérios serem diferentes, verifica-se que a periodização de Hughes e Barroso e a paradigmatização, tomando como referência critérios epistemológicos, de Ribbins, England e Burrel ; Morgan, apresentam algumas analogias.

O segundo grupo é constituído pelos restantes oito autores, que têm, em comum, o facto de apresentarem indiferentemente, sob a designação de modelos, abordagens ou teorias, o estudo das organizações educativas segundo parâmetros e critérios que remetem directamente para as práticas da administração (BARROSO, 1995a , p. 461) e para teorização da organização e administração educacional, referenciando-a à evolução das teorias da administração em geral (SILVER, 1983). 
Exceptuando o caso dos Modelos Democráticos referidos por Bush (1989), cuja definição se revela indomável em termos classificatórios, do conjunto de todas as tipologias consideradas, pudemos identificar seis grandes grupos de modelos/teorias:

\author{
1 - Clássicos/Burocracia \\ 2 - Relações Humanas/Abordagem Comportamental \\ 3 - Estruturais/Institucionais \\ 4 - Sistemas Abertos/Abordagem Contingencial \\ 5 - Simbólicos/Ambiguidade \\ 6 - Políticos/Críticos
}

Tais grupos, de certa forma, "acompanham", em termos evolutivos, as teorias das organizações referidas no ponto anterior.

No entanto, verificam-se algumas diferenças que importa referir e tentar esclarecer. Como pode verificar-se pelos tópicos e autores de referência que identificam as grandes classificações dos autores do primeiro grupo, nomeadamente Ribbins (exceptuando a inclusão dos Sistemas Debilmente Acoplados), Hughes, England e Barroso, no primeiro momento considerado, as teorias e correntes articulam-se, em absoluto, com as teorias da administração em geral.

As organizações educativas são percebidas como organizações que em nada se diferenciam das restantes organizações. Não há, portanto, lugar a uma teorização própria. Só com o "New Movement” (BARROSO, 1995b, p. 36) se verifica uma preocupação de construção de uma teoria das organizações educativas e da administração educacional. A emergência de uma consciência de que as organizações educativas são organizações peculiares em alguns aspectos é um dos principais contributos do esforço de autonomização da teorização sobre as organizações educativas que, nesta altura, se verifica. No entanto, porque os fundamentos de tal construção estão ainda ancorados numa forte concepção instrumental da administração, cedo é confrontada com contradições teóricas inultrapassáveis, nomeadamente a impossibilidade de conciliar o princípio da separação entre factos e valores (EVERS ; LAKOMSKY, 1991) e as peculiaridades das organizações educativas, das quais a menos importante não é certamente a de serem atravessadas, em todos os sentidos, pelas dimensões ética e ideológica.

É natural, portanto, que o "ataque" de Greenfield ao "New Movement" se fundamente, especialmente, nas críticas a Herbert Simon (GREENFIELD; RIBBINS, 1993, p. 137; BARROSO, 1995b, p. 39). Na base dessas críticas está, em última análise, o surgimento de uma outra concepção das organizações educativas, 
genuinamente gerada, de forma autónoma, mas não descontextualizada do movimento mais geral da sociologia das organizações.

Neste caso, a diferença fundamental, no percurso paralelo das teorias da administração educacional e das teorias da administração em geral, reside no facto de haver, em termos da produção teórica, uma mediação operada pela sociologia das organizações. A autonomização da administração educacional resulta do corte do cordão umbilical que a ligava às teorias da administração de empresas. Ambas vão, do ponto de vista epistemológico e teórico, beber à reflexão teórica da sociologia das organizações, mas cada uma delas apropria-se desta reflexão de acordo com as suas necessidades e peculiaridades. Isto explica porque as linhas de desenvolvimento teórico, subsequente, em ambas as áreas, apresentam paralelismos, cruzamentos e contributos mutuamente enriquecedores.

Esta correspondência e paralelismo são visíveis, por exemplo, entre as teorias que referenciámos nos grupos Sistemas de Acção Concreta e "Teorias Emergentes" e nos paradigmas, períodos e modelos/teorias que vimos referindo, e que podem ser visualizadas no seguinte quadro 5 .

\section{Quadro 5 - Teorias das Organizações e Teorias das Organizações Educativas: correspondências na teorização recente}

\begin{tabular}{|c|c|}
\hline Teorias das Organizações & $\begin{array}{c}\text { Teorias das Organizações } \\
\text { Educativas }\end{array}$ \\
\hline $\begin{array}{l}\text { Sistemas de Acção Concreta } \\
\text { - Sistema de Acção Concreta } \\
\text { - Metáfora - Sistema Político } \\
\text { - Metáfora - Instrumento de Dominação } \\
\text { - Abordagem Estratégica } \\
\text { - Contingência estratégica }\end{array}$ & $\begin{array}{l}3^{\circ} \text { Período - 1970-... (Barroso) } \\
\text { Perspectivas Contemporâneas (Hughes) } \\
\text { Interpretativo (Burrel ; Morgan) } \\
\text { Construções Sociais - Indivíduo (Pfeffer) } \\
\text { Modelos Políticos (Bush) } \\
\text { Ordem Empiricamente Contingente } \\
\text { (Ribbins) }\end{array}$ \\
\hline $\begin{array}{l}\text { Teorias Emergentes: } \\
\text { - Anarquismo } \\
\text { - Existencialismo } \\
\text { - Marxismo } \\
\text { - Accionalismo } \\
\text { - Paradigma da Complexidade } \\
\text { - Metáfora - Cérebro } \\
\text { - Fluxo e Informação } \\
\text { - Prisão do Psiquismo }\end{array}$ & $\begin{array}{l}\text { 3 Período - 1970-... (Barroso) } \\
\text { Assunção do Conflito (Ribbins) } \\
\text { Estruturalismo Radical (Burrel ; Morgan) } \\
\text { Humanismo Radical (Burrel ; Morgan) } \\
\text { Modelos de Ambiguidade e Subjectivos } \\
\text { (Bush) } \\
\text { Modelos Simbólicos (Borrel Felip) }\end{array}$ \\
\hline
\end{tabular}


Esta correspondência, como pode verificar-se, se não é, na maior parte dos casos, linear em termos das próprias designações oferece, no entanto, um quadro geral das linhas de evolução prováveis e possíveis, nos dois campos das teorias das organizações e da administração. Acima de tudo, ela oferece uma comprovação do que afirmámos antes. $\mathrm{O}$ desenvolvimento das teorias das organizações e administração educativas, cada vez mais, se liberta da tutela das teorias da administração empresarial.

Renovando as precauções enunciadas quando do exercício idêntico a propósito das teorias das organizações, a utilização da grelha de leitura, explicitada no início, conduz-nos ao quadro 6.

\section{Quadro 6 - Evolução das Teorias das Organizações Educativas}

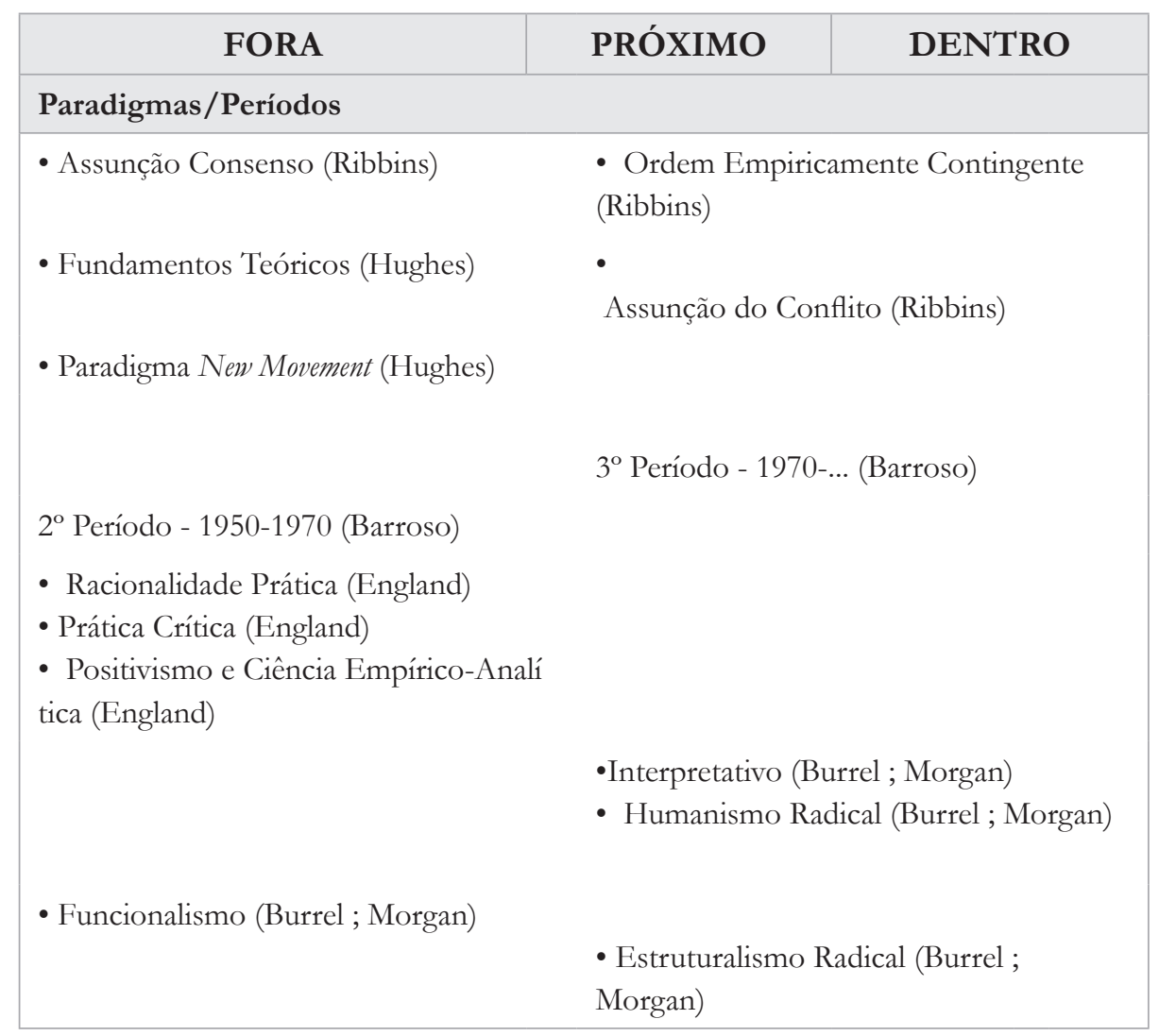




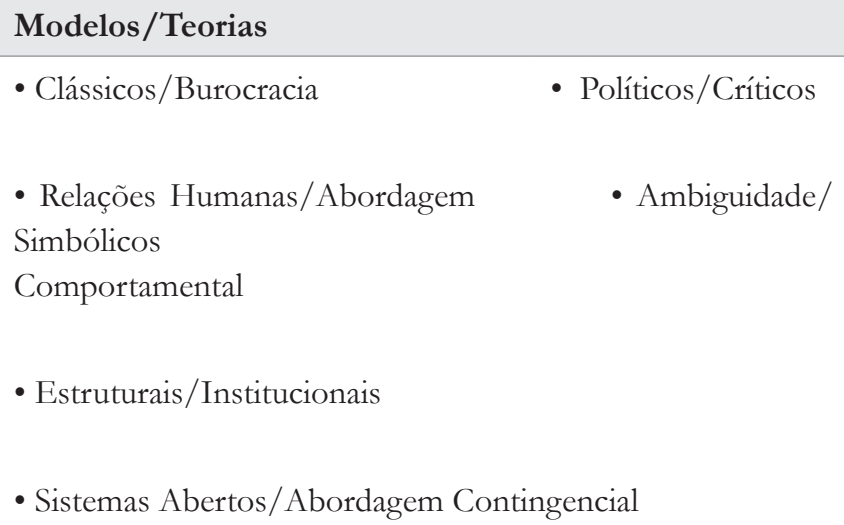

- Clássicos/Burocracia

- Políticos/Críticos

- Relações Humanas/Abordagem

- Ambiguidade/

Simbólicos

Comportamental

- Estruturais/Institucionais

- Sistemas Abertos/Abordagem Contingencial

As organizações educativas, enquanto organizações sociais, no contexto da evolução das teorias das organizações antes apresentadas, não podem fugir à complexidade que perpassa pelas perspectivas mais recentes da teorização sobre as organizações. As noções de sistema debilmente acoplado e anarquia organizada são instrumentos conceptuais e analíticos adequados para a compreensão da natureza imprecisa da construção e funcionamento das organizações educativas em geral e das escolares, em particular (ver, a este propósito, OGAWA, 1984), enquanto sistemas concretos de acção (CROZIER ; FRIEDBERG, 1977; FRIEDBERG, 1995). E, neste sentido, se bem que possam ser consideradas como organizações "domesticadas" (MARTIN ; WILLOWER, 1981, p. 83), do ponto de vista económico e político-administrativo, as organizações educativas podem ser, numa perspectiva sociocultural e simbólica, vistas como organizações "selvagens".

Num ponto algures, entre os momentos "Próximo" e "Dentro", deverá situar-se, em termos conceptuais, como organização educativa.

Considerá-la como uma construção social onde os actores organizacionais, quotidianamente, constróem na ambiguidade e no conflito, mas também na procura da certeza e do consenso, através da permuta de bens materiais, culturais e simbólicos, uma ordem constantemente negociada, cujas finalidades sendo formalmente expressas como de transmissão e partilha social e cultural, dificilmente são impressas nos termos originalmente concebidos, devido à natureza imprecisa da sua própria construção; é a forma de mobilizar uma pluralidade contributos teóricos, numa perspectiva que oferece um instrumento analítico com grandes potencialidades para o seu estudo. 


\section{REFERÊNCIAS}

ALLISON, Derek J. Toward an improved understanding of the organizational nature of schools. Educational Administration Quarterly, vol. 19(4), p. 7-34, 1983.

Ansart, Pierre. Les sociologies contemporaines. Paris: Editions du Seuil, 1990.

Audry, Colette. Filósofos de todos os tempos - Sartre. Lisboa: Estúdios Cor., 1972.

Bakounine, M. O Estado: alienação e natureza. In: Guérin, Daniel. O Estado, a democracia burguesa, a prática revolucionária e o anarquismo - Antologia. Porto: Livraria Paisagem, (s.d.).

Baldridge, J. Victor ; Deal, Terrence, eds. The dynamics of organizational change in education. Berkeley: McCutchan Publishing, 1983.

Ballé, Catherine). Sociologie des organisations. Paris: Presses Universitaires de France, 1992.

Barroso, João. Organização pedagógica e a administração dos liceus (1836-1960). Dissertação de Doutoramento (policopiada). Lisboa: Faculdade de Psicologia e de Ciências da Educação - Universidade de Lisboa, 1993.

Barroso, João. Organização pedagógica e a administração dos liceus (18361960). Lisboa: Fundação Calouste Gulbenkian e Junta Nacional de Investigação Científica,1995a.

Barroso, João. Para uma abordagem teórica da Reforma da Administração Escolar: a distinção entre 'direcção' e 'gestão'. Revista Portuguesa de Educação, vol. 8(1), pp. 33-56, $1995 \mathrm{~b}$.

Bernoux, Philippe (1985). La Sociologie des organisations. Paris: Éditions du Seuil.

Bolman, Lee G. ; Deal, Terrence E. Modern approaches to understanding and managing organizations. California. San Francisco: Jossey-Bass, 1984.

Borrel Felip, Nuria. Organización escolar-Teorias obrelas currientes Cientificas. Barcelona: Humanitas.

Bottery, Mike. The ethics of educational management.London: Cassell Education, 1993. 
Boutinet, Jean-Pierre. Anthropologie du project. Paris: Presses Universitaires de France, 1990.

Burnes, Bernard. Managing change. London: Pitman Publushing, 1992.

Burrell, Gibson; Morgan, Gareth. Sociological paradigms and organisational analysis. Elements of the sociology of corporate life. Portsmouth, New Hampshire: Heinemann Educational Books, 1979.

Bush, Tony. Theories of educational management. London: Harper; Row, 1986.

CAA-ME (Conselho de Acompanhamento e Avaliação). Avaliação do regime de direcção, administração e gestão dos estabelecimentos de educação pré-escolar e dos ensinos básico e secundário - Relatório. Lisboa: Ministério da Educação, 1996.

Chanlat, Jean-François ;Séguin, Francine, (dir). L’Analyse des organisations. Une Anthologie Sociologique. Tome II - Les Composantes de l'Organisation. Québec: Gaetan Morin, 1987.

Chanlat, Jean-François ; Séguin, Francine, (dir). L’Analyse des organisations. Une Anthologie Sociologique. Tome I - Les Theories de l'Organisation. Québec: Gaetan Morin, 1992.

Chiavenato, Idalberto. Introdução à teoria geral da administração. S. Paulo: McGraw-Hill, 1983.

Cohen, M. D. ;March, J. G. ;Olsen, J. P. A garbage can model organizational choice. Administrative Science Quarterly, 17, p. 1-25, 1972.

Crozier, Michel. Le phénomene bureaucratique. Paris: Editions Seuil, 1964.

Crozier, Michel ; Friedberg, Erhard. L'acteur et le système. Paris: Editions du Seuil, 1977.

Cury, António. Organização e métodos. São Paulo: Atlas, 1990.

De Rosnay, Joel. Le macroscope - Vers une vision globale. Paris: Editions du Seuil, 1975.

Dubet, François. Sociologia da experiência. Lisboa: Instituto Piaget, 1996. 
Durkheim, Emile. As Regras do método sociológico. In: , M. Braga da (org.) Teorias sociológicas. $1^{\circ}$ Volume, Os Fundadores e os Clássicos. Lisboa: Fundação Calouste Gulbenkian, p. 301-12, 1995.

Ecker, G. Theories of educational organization: modern. In: Husén, Torsten; Postlehwaite, T. Neville (eds). The international encyclopedia of education. Oxford: Pergamon Press, p. 5256-9, 1985.

England, Gerry. "Tres formas de entender la administración educativa”.In: Smyth, W. John et al. Teoría critica de la administración educativa. Valência: Universitat de Valência, p. 75-112, 1989.

Evers, Colin W. ; Lakomski, Gabrielle. Knowing educational administration. Oxford: Pergamon Press, 1991.

Fayol, Henri. Principes généraux d'administration. In: Chanlat, Jean-François; Séguin, Francine, (dir). L'Analyse des organisations. Une anthologie sociologique. Tome I - Les theories de l’organisation. Québec: Gaetan Morin, p. 95-118, 1992.

Friedberg, Erhard. O Poder e a regra. Dinâmicas da acção organizada. Lisboa: Instituto Piaget, 1995.

Greenfield, Thomas B. Theories of educational organization: a critical perspective. In: Husen, T. ; Postlehwaite, T. (ed). The international encyclopedia of education. Oxford: Pergamon Press, p. 5240-51. 1985.

Greenfield, Thomas B.; Ribbins, Peter. Greenfield on educational administration. Towards a Human Science. London: Routledge, 1993.

Guérin, Daniel O Estado, a democracia burguesa, a prática revolucionária e o anarquismo - Antologia. Porto: Livraria Paisagem, (s.d.).

Halpin, Andrew. The development of theory in educational administration. In: Halpin, Andrew (ed). Administrative theory in education. New York: The Macmillan Company, p. 1-19, 1967.

Hughes, Mereddyd. Theory and practice in educational management. In: Hughes, Mereddyd ; Ribbins, Peter ;Thomas, Hywel, (eds). Managing education - The system and the institution. London: Cassell Education, p. 3-42, 1987.

Jesuíno, Jorge Correia. Processos de liderança. Lisboa: Presença, 1987. 
Kropotkine, P. Sobre o governo representativo ou parlamentarista. In: Guérin, Daniel. O Estado, a democracia burguesa, a prática revolucionária e o anarquismo - Antologia. Porto: Livraria Paisagem. (s.d.).

Lefebvre, Henri. Sociologie de Marx. Paris: Presses Universitaires de France, 1968.

Lunemberg, Fred C. ; Ornstein, Allan C. Educational administration. Concepts and practices. Belmont: Wadsworth Publishing Company, 1991.

Malatesta, E. Révolution et Réaction. In: Chanlat, Jean-François; Séguin, Francine (dir). L'Analyse des organisations. Une anthologie sociologique. Tome I - Les Theories de l'Organisation. Québec: Gaetan Morin, p. 331-42, 1992.

March, James G. ; Simon, Herbert A. Les organizations. Paris: Dunod, 1979.

Martin, William J. ; Willower, Donald J. The Managerial Behavior of High School Principals. Educational administration quarterly, vol. 17(1), p. 69-90, 1981.

Marx, Karl . Teses sobre Feuebarch. In: Marx, Karl ; Engels, Friedrich, Obras escolhidas. - Tomo I, Lisboa: Editorial Avante, p. 1-3, 1982.

Morgan, Gareth. Images de l'organisation. Laval (Québec): Les Presses de l’Université Laval. Editions Eska, 1989.

Muchielli, Alex. Psycho-sociologie des organisations. Paris: Librairies Techniques. Entreprise Moderned Edition, 1977.

Ogwa, Rodney T. Teachers and administrators: elements of the information processing repertoires of schools. Educational administration quarterly, vol. 20(2), p. 5-24, 1984.

Ogwa, Rodney T. Theories of educational organization: classical. In: Husen, T. ; Postlehwaite, T. (eds). The international encyclopedia of education. Oxford: Pergamon Press, p. 5251-6, 1985.

Ouchi, William G. ; Wilkins, Alan L. Organizational culture. In: Westoby, Adam, (ed). Culture and power in educational organizations. Milton Keynes: Open University Press, p. 223-53, 1988.

Petitt, François. Introduction à la psycho-sociologie des organisations. Toulouse: Privat, 1991.

Pfeffer, Jeffrey. Organizations and organization theory. Boston: Pitman Pub, 1982. 
Piettre, André. Marxismo. Rio de Janeiro: Zahar Editores. 1969.

Proudhon, P. J. Mutualité, ordre et liberté. In : Chanlat, Jean-François; éguin, Francine, (dir). L'analyse des organisations. Une anthologie sociologique. Tome I - Les theories de l'organisation. Québec: Gaetan Morin, p. 323-30, 1992.

Ribbins, Peter. Organization theory and the study of educational institutions. In: Hughes, Mereddyd ; Ribbins, Peter; Thomas, Hywel, (eds). Managing education

- The system and the institution. London: Cassell Education, p. 223-61.

Saenz Barrio, Oscar. Perspectivas actuales de la organización. In: Saenz Barrio, Oscar et al. Organización escolar. Una perspectiva ecológica. Alcoy: Editora Marfil S. A., 1993.

Sanches, Maria de Fátima Chorão. Cultura organizacional - Um paradigma de análise da realidade escolar. Lisboa: G.E.P.- Ministério da Educação, 1992.

Santos, Boaventura de Sousa. Introdução a uma ciência pós-moderna. Porto: Afrontamento, 1993a.

Santos, Boaventura de Sousa. Um discurso sobre as ciências. Porto: Afrontamento1993b.

Sartre, Jean-Paul. O Existencialismo é um humanismo. In: Ferreira, Vergílio; Sartre, Jean-Paul. O Existencialismo é um humanismo. Lisboa: Editorial Presença, (s.d.).

Scott, W. Richard. Organizations. Rational, natural and open systems. Englewood Cliffs: Prentice-Hall, 1987.

Silver, Paula F. Educational administration. Theoretical perspectives on practice and research. New York: Harper ; Row, 1983.

Taylor, F. W. Principes d'organisation scientifique des usines. In : Chanlat, JeanFrançois ; Séguin, Francine. (dir). L'analyse des organisations. Une anthologie sociologique. Tome I - Les theories de l'organisation. Québec: Gaetan Morin, p. 79-94.

Touraine, Alain. Pour la sociologie. Paris: Editions du Seuil, 1974.

Tyler, William B. The organizational structure of the school In: Westoby, Adam, ed. Culture and power in educational organizations. Milton Keynes: Open University Press, p. 15-41, 1988. 
Wahl, Jean. As filosofias da existência. Lisboa: Publicações Europa-América, 1962.

Weber, Max. Le type pur de la domination légale. In: Chanlat, Jean-François; Séguin, Francine, (dir). L'analyse des organisations. Une anthologie sociologique. Tome I - Les theories de l'organisation. Québec: Gaetan Morin, p. 119-2, 1992.

Weick, Karl E. Educational organizations as Loosely Coupled Systems. Administrative science quarterly, vol. 21(1), p. 1-19, 1976.

LUÍS LEANDRO DINIS é professor aposentado do ensino secundário; mestre em Ciências da Educação pela Faculdade de Psicologia e de Ciências da Educação Universidade de Lisboa - PT. Foi docente assistente convidado nesta Faculdade; é membro da direcção do FPAE, responsável pela coordenação redatorial da Revista “Administração Educacional". E-mail: 1lvdinis@gmail.com

Recebido em janeiro de 2015 Aprovado em fevereiro de 2015 